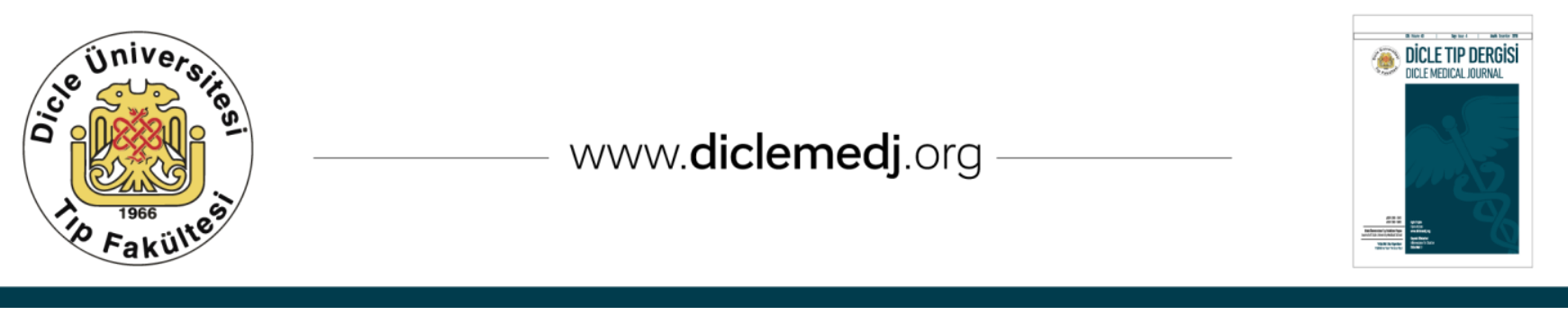

\title{
Hepatoselüler Karsinom ve Diğer Karaciğer Tümörlerinin Ayrımında Difüzyon Ağırlıklı Manyetik Rezonans Görüntülemenin Etkinliği
}

\author{
Hasan Erdoğan1, Serdar Arslan², Mehmet Sedat Durmaz ${ }^{3}$ \\ 1 Aksaray Üniversitesi Eğitim ve Araştırma Hastanesi, Radyoloji Kliniği, Aksaray, Türkiye ORCID: 0000-0001-8109-8537 \\ 2 Sağlık Bilimleri Üniversitesi Konya Eğitim ve Araștırma Hastanesi, Radyoloji Kliniği, Konya, Türkiye ORCID: 0000-0001-7984-4326 \\ 3 Selçuk Üniversitesi Tıp Fakültesi, Radyoloji Anabilim Dal, Konya, Türkiye ORCID: 0000-0002-1340-2477
}

Geliş: 05.07.2019; Revizyon: 21.10.2019; Kabul Tarihi: 29.10.2019

\section{Öz}

Amaç: Difüzyon ağırlıklı manyetik rezonans görüntüleme (MRG), dokulardaki su moleküllerinin difüzyonuna bağlı hareketlerinin ölçümü prensibine dayanan bir MRG yönetimidir. Hepatoselüler karsinom (HSK), karaciğerin en sık görülen primer malign tümörü olup, erken evrede diğer lezyonlardan ayırt edilebilmesi küratif tedavi açısından çok önemlidir. Biz bu çalışmada, HSK'yı, metastaz, kolanjiokarsinom ve fokal nodüler hiperplazi (FNH) gibi diğer sık görülen karaciğer fokal lezyonlarından ayırt etmede difüzyon MRG'nin etkinliğini araştırmayı amaçladık.

Yöntemler: Histopatolojik olarak HSK, metastaz, kolanjiokarsinom ve FNH tanısı mevcut olan toplam 157 hastanın difüzyon MRG görüntüleri retrospektif olarak taranarak, lezyonların görünür difüzyon katsayısı (ADC, apparent diffusion coefficient) ölçümleri yapıldı. ADC değerleri istatistiksel olarak karşılaştırılarak, özellikle HSK'yı diğer lezyonlardan ayırt etmede ADC değerlerinin tanıya katkı sağlayıp sağlamadığı değerlendirildi.

Bulgular: Ortalama ADC değerleri, çalışmamıza dahil ettiğimiz 38 HSK olgusunda 836,6 \pm 182,4 x10-6 mm2/sn, 22 kolanjiokarsinom olgusunda 801,4 $\pm 239,4 \times 10-6 \mathrm{~mm} 2 / \mathrm{sn}, 77$ metastaz olgusunda 923,7 $\pm 279,0 \times 10-6 \mathrm{~mm} 2 / \mathrm{sn}$ ve 20 FNH olgusunda 1202,9 \pm 139,3 x10-6 mm2/sn olarak ölçüldü. HSK ile FNH'ın ADC değerleri arasında anlamlı istatistiksel fark saptandı. HSK ile diğer fokal lezyonlar arasında ise istatistiksel olarak anlamlı fark saptanmadı.

Sonuç: HSK'yı FNH'dan ayırt etmede ADC değerleri tanıya ek katkı sağlarken, HSK'yı kolanjiokarsinom ve metastazdan ayırt etmede ADC değerleri tanıya ek katkı sağlamamaktadır.

Anahtar kelimeler: Karsinoma, Hepatoselüler, Karaciğer, Difüzyon MRG, ADC 


\title{
Efficacy of Diffusion Weighted Magnetic Resonance Imaging in Distinguishing Hepatocellular Carcinoma and Other Liver Tumors
}

\begin{abstract}
Objective: Diffusion-weighted magnetic resonance imaging (MRI) is an MRI method based on the principle of measuring diffusion-induced movements of water molecules in tissues. Hepatocellular carcinoma (HCC) is the most common primary malignant tumor of the liver and it is very important to distinguish it from other lesions in the early stage for curative treatment. In this study, we aimed to investigate the efficacy of diffusion MRI in differentiating HCC from other common liver focal lesions such as metastasis, cholangiocarcinoma and focal nodular hyperplasia (FNH).

Methods: The diffusion MRI images of 157 patients with histopathological diagnosis of HCC, metastasis, cholangiocarcinoma and FNH were retrospectively analyzed and apparent diffusion coefficient (ADC) of the lesions were measured. The ADC values were compared statistically and it was evaluated whether ADC values contributed to the diagnosis, especially in distinguishing HCC from other lesions.

Results: The mean ADC values were measured as $836.6 \pm 182.4 \times 10-6 \mathrm{~mm} 2 / \mathrm{sn}$ in 38 HCC cases, $801.4 \pm 239.4 \times 10-6$ $\mathrm{mm} 2 / \mathrm{sn}$ in 22 cholangiocarcinoma cases, $923.7 \pm 279 \times 10-6 \mathrm{~mm} 2 / \mathrm{sn}$ in 77 metastasis cases and $1202.9 \pm 139.3 \times 10-6$ $\mathrm{mm} 2 / \mathrm{sn}$ in $20 \mathrm{FNH}$ cases. There was a statistically significant difference between ADC values of HCC and FNH. There was no statistically significant difference between HCC and other focal lesions.

Conclusion: ADC values in differentiating HSC from FNH provide additional contribution to diagnosis, whereas ADC values in differentiating HSC from cholangiocarcinoma and metastasis do not contribute to diagnosis.
\end{abstract}

Keywords: Carcinoma, Hepatocellular, Liver, Diffusion MRI, ADC.

\section{GíRIş}

Difüzyon ağırlıklı manyetik rezonans görüntülemede (MRG) dokulardaki su moleküllerinin difüzyona bağlı hareketleri ölçülür. Difüzyon MRG klinik pratikte en yaygın olarak akut serebral iskemi tanisinda kullanılır ${ }^{1}$. Abdominal incelemelerde ise fokal lezyonların ayırıcı tanısında ve apse tanısinda sıklıkla kullanılmaktadır ${ }^{2,3}$. Konvansiyonel MRG sekanslarına göre çok kısa sürede elde edilebilen difüzyon $\mathrm{MRG}$, günümüzde çoğu merkezde rutin abdomen MRG protokollerinin bir parçası haline gelmiştir. Diffüzyon MRG incelemesinde düşük ve yüksek "b" değerinde (MR gradient gücü ve süresini gösteren bir faktör) difüzyon görüntüler ve görünür difüzyon katsayısı (ADC, apparent diffusion coefficient) görüntüleri elde edilir. Difüzyon ağırlıklı MRG'de doku ve lezyonlardaki sinyal kaybının görüntü üzerinde işaretlenerek ölçülebilir (kantitatif) bir hale getirilmesi sonucu ADC görüntüler oluşur. Malign lezyonlarda olduğu gibi hücre yoğunluğunun arttığı dokularda su moleküllerinin difüzyonu kısıtlanır ${ }^{4}$. Difüzyon MRG'de bu lezyonlar hiperintens sinyal özelliği kazanırlar, ADC haritasında ise düşük sayısal değerler gösterirler. Kantitatif ölçümler bu ADC görüntüleri üzerinden, ADC değeri (mm2/sn) ölçülerek yapılır. ADC değeri, difüzyon artıșı gösteren benign lezyonlarda genellikle yüksek iken, difüzyon kısıtlanması gösteren malign lezyonlarda genellikle düşük bulunur (Resim 1).

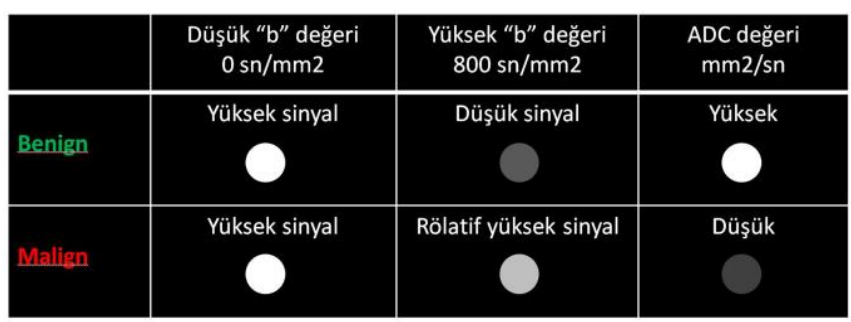

Resim 1. Benign ve malign lezyonların farklı "b" değerlerinde yapılan difüzyon ağırlıklı MRG'de sinyal özellikleri ve ADC haritalamadaki sinyal değerleri 
Hepatoselüler karsinom (HSK) karaciğerin en sık görülen primer malignitesidir ve genellikle sirozdan kaynaklanır ${ }^{5,6}$. HSK'yi radyolojik olarak küratif tedavi evresinde yakalayabilmek önemlidir ${ }^{7}$. Son yıllarda HSK'ların erken tespit edilebilmesi için yoğun çaba sarf edilmektedir. Karaciğerde HSK dışında en sık görülen başlıca kitlesel lezyonlar, hemanjiom, kolanjiyokarsinom, metastaz ve fokal nodüler hiperlazi (FNH) 'dir'. Hemanjiomlar, difüzyon MRG'de yüksek ADC değerleri göstermeleri ve kontrastlı incelemede tipik periferik nodüler kontrast tutulumu göstermeleri ile ayırt edilebilir ${ }^{9}$. Diğer lezyonlarda ise ayırıcı tanıda ek bilgi sağlamak amacıyla difüzyon ağırlıklı MRG'ye daha fazla ihtiyaç duyulmaktadır.

Biz bu çalışmada histopatolojik tanıları baz alarak HSK'yi, intrahepatik kolanjiokarsinom, metastaz ve FNH gibi karaciğer fokal lezyonlarından ayırt etmede difüzyon ağırlıklı MRG'nin etkili olup olmadığını araştırmayı amaçladık.

\section{YÖNTEMLER}

$\mathrm{Bu}$ çalışmanın yapılması için Selçuk Üniversitesi Tıp Fakültesi Girişimsel Olmayan Klinik Araştırmalar Etik Kurulu'ndan onam (16.01.2019 tarih ve 2019/24 sayılı) alınmıştır.

$\mathrm{Bu}$ çalışma Konya Eğitim ve Araştırma Hastanesi'nde retrospektif olarak, karaciğer fokal lezyonu olan hastaların 2014-2018 yılları arasındaki difüzyon ağırlıklı MRG görüntüleri taranarak yapıldı. Karaciğer fokal lezyonlarının tanısında altın standart yöntem histopatolojik inceleme olduğundan, yalnızca histopatolojik tanısı mevcut olan hastalar çalışmaya alındı. HSK, metastaz, kolanjiokarsinom ve FNH olan olgular çalışmaya dahil edildi. Tanısı için biyopsi gerekmeyen ve tanısı radyolojik olarak daha kolay konulabilen benign lezyonlar olan kist ve hemanjiomlar çalışmaya dahil edilmedi. Kanama riski nedeniyle biyopsiden kaçınılan adenomlar ve çok nadir görülen diğer fokal karaciğer lezyonlarından patolojik tanısı olan yeterli sayıda vaka olmadığından, bu lezyonlar çalışmaya alınmadı. Birden fazla lezyonu olan hastalarda sadece histopatolojik tanısı mevcut olan lezyon çalışmaya alındı. Toplam 157 hastada 157 adet lezyon değerlendirildi.

Görüntülemede 1.5 T MRG cihazı (Siemens Healthineers, Erea, Germany) ile yapıldı. Aksiyal planda, "single shot echoplanar spin" tekniği ile 3 farklı $b$ değerinde $(b=50, b=400$, $\mathrm{b}=800 \mathrm{sn} / \mathrm{mm} 2$ ) difüzyon ağırlıklı görüntüler ve ADC haritalama görüntüsü elde edildi. ADC haritalarında lezyonlar üzerine dairesel ROI yerleștirilerek ortalama ADC değerleri belirlendi. Ölçümler heterojen görünümdeki HCC'lerde arteriyel fazda kontrast tutan solid komponentten yapıldı. Homojen solid lezyonlarda ise mümkün olduğunca lezyonunun tamamından ölçüm yapıldı.

Lezyonların tanısinda altın standart kabul edilen histopatolojik sonuçlar ile lezyonların ADC değerleri karşılaştırılarak, lezyonların ADC değerleri arasında anlamlı fark olup olmadığ değerlendirildi. İstatistiksel analiz için Student $\mathrm{T}$ testi kullanıldı. 0.05'ten küçük $\mathrm{P}$ değeri istatistiksel olarak anlamlı kabul edildi.

\section{BULGULAR}

Hastaların 88'i (\%56) erkek, 69'u (\%44) kadındı. Hastaların yaş ortalaması 58,8 (30-89) olarak saptand. Patolojik tanılarına göre lezyonların 38'i HSK, 22'si intrahepatik kolanjiokarsinom, 77'si metastaz ve 20'si FNH idi. Metastazı olan hastaların primer malignite olarak 28'inde kolon kanseri, 16'sında invazif duktal meme kanseri, 10'unda akciğer kanseri, 8'inde pankreas kanseri ve 15'inde ise diğer maligniteler vardı. Çalışmaya dahil edilen lezyonların patolojik tanısı, sayısı, boyutu, ADC değerleri ve hastaların yaş ortalamaları Tablo I'de gösterilmiştir.

Student T testi kullanılarak lezyonların ADC değerleri arasında ikili karşılaştırmalar yapıldığında HSK ile FNH'ın ADC değerleri arasında anlamlı fark bulunmuştur $(p=0.001)$. HSK ile diğer fokal lezyonlar arasında ise 
istatistiksel olarak anlamlı fark saptanmamıştır (Tablo II). Lezyonlara ait örnek görüntüler ve ADC ölçümleri Resim 2 'de gösterilmiştir.

Tablo I: Çalışmaya dahil edilen lezyonların patalojik tanısı, lezyon sayısı, boyutu ve ADC değerleri ile hastaların yaş ortalamaları (Ortalama \pm SD)

\begin{tabular}{|l|c|c|c|c|}
\hline Patolojik tanı & $\begin{array}{c}\text { Lezyon } \\
\text { sayısı } \\
(\mathbf{\%})\end{array}$ & $\begin{array}{c}\text { Lezyon } \\
\text { boyutu } \\
\text { (mm) }\end{array}$ & $\begin{array}{c}\text { ADC değeri } \\
\mathbf{( x 1 0 - 6} \\
\left.\mathbf{m m}^{2} / \mathbf{s n}\right)\end{array}$ & Yaş (yıl) \\
\hline HSK & 38 & $70,9 \pm$ & $836,6 \pm$ & $67,5 \pm$ \\
& $(24,2)$ & 46,5 & 182,4 & 13,2 \\
\hline \multirow{2}{*}{ Kolanjiokarsinom } & $22(14)$ & $56,6 \pm 23,4$ & $801,4 \pm$ & $56,5 \pm$ \\
& 77 & $38,7 \pm$ & $923,7 \pm$ & $61,7 \pm$ \\
Metastaz & $(49,1)$ & 23,1 & 279,0 & 14,8 \\
\hline \multirow{2}{*}{ FNH } & 20 & $30,2 \pm$ & $1202,9 \pm$ & $33,7 \pm$ \\
& $(12,7)$ & 10,8 & 139,3 & 11,1 \\
\hline \multirow{2}{*}{ Toplam } & 157 & $47,9 \pm$ & $921,0 \pm$ & $58,8 \pm$ \\
& $(100)$ & 27,2 & 264,2 & 17,7 \\
\hline
\end{tabular}

HSK: hepatselüler karsinom; FNH: fokal nodüler hiperplazi; ADC: apparent diffusion coefficient (görünür difüzyon katsayısı)

Tablo II: HSK ile diğer lezyonların ADC değerlerinin istatistiksel olarak karşılaștırılmaları sonucu elde edilen $\mathrm{P}$ ve T değerleri

\begin{tabular}{|l|c|c|}
\hline Karşılaştırılan lezyonlar & P değeri & T değeri \\
\hline HSK ve Kolanjiokarsinom & 0,523 & $-0,642$ \\
\hline HSK ve Metastaz & 0,083 & 1,746 \\
\hline HSK ve FNH & $\mathbf{0 , 0 0 1} *$ & $\mathbf{- 7 , 8 4 3} *$ \\
\hline
\end{tabular}

*anlamlı istatistiksel fark vardır

\section{TARTIŞMA}

Karaciğer fokal lezyonların sık görülmesi nedeniyle önemli bir organdır. Karaciğer benign ve malign lezyonlarının klinik olarak ayırt edilmesi çok önemlidir. Çünkü benign lezyonlarda tedavi genellikle gerekli değilken, malign lezyonlarda özellikle erken evrede en etkili tedavi yöntemi cerrahi rezeksiyondur10. Yapılan bazı çalışmalara göre cerrahi rezeksiyon yapılan küçük boyutlu HSK'lı olguların 5 yıllık sağ kalımı \%80'in üzerindedir ${ }^{11}$. Bu yüzden HSK lezyonlarını küçük boyutta iken saptamak ve diğer lezyonlardan ayırmak önemlidir.

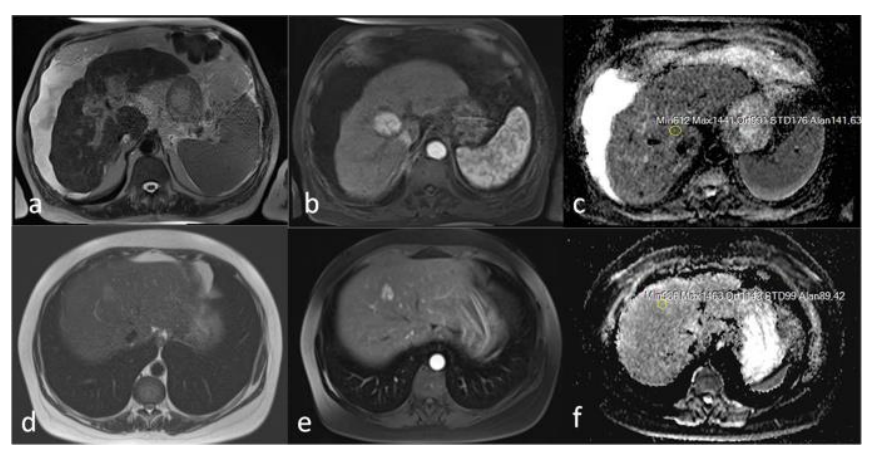

Resim 2. HCC histopatolojik tanısı olan 74 yaşındaki erkek hastada karaciğer segment 8'de T2A görüntüde (a) hiperintens izlenen, arteriyel fazda (b) yoğun kontrast tutan lezyonun ADC değeri (c) 991x10-6 mm2/sn ölçülmüştür. FNH histopatolojik tanısı olan 32 yaşındaki kadın hastada karaciğer segment 4 'te T2A görüntüde (d) hafif hiperintens izlenen, arteriyel fazda (e) kontrast tutan lezyonun ADC değeri (f) 1463x10-6 mm2/sn ölçülmüştür.

Difüzyon, su moleküllerinin mikroskopik rastgele hareketlerine verilen isimdir. Difüzyon MRG ile su moleküllerinin difüzyonunun in vivo ve kantitatif olarak ölçülmesi mümkündür ${ }^{1}$. Selülaritenin yüksek olduğu malign tümörlerde su moleküllerinin difüzyonu kısıtlanır. Kistler ve diğer benign lezyonlarda ise su molekülleri serbest olarak hareket edebilir ${ }^{4}$. Difüzyon MRG'de lezyonlardaki difüzyon kısıtlanmasının ölçülebilir (kantitatif) bir hale getirilmesi sonucu ADC görüntüler oluşur.

Literatürde yapılan çalışmaların çoğunda karaciğer benign lezyonlarının ADC değerlerinin malign lezyonlardan daha yüksek olduğu bildirilmiştir ${ }^{2,12,13}$. Özellikle kist ve hemanjiomların ADC değerlerinin diğer fokal karaciğer lezyonlarından belirgin şekilde yüksek olduğu yapılan çalışmalarda gösterilmiștir ${ }^{2,14}$. Kist ve hemanjiomların tanısı radyolojik olarak kolay konulabildiğinden ve biyopsi gerekmediğinden, ayrıca bu lezyonlar ile ilgili literatürde yapılmış olan çok sayıda 
çalışmada, bu lezyonların ADC değerlerindeki artışın çok belirgin olduğu konusunda görüş birliği olduğundan, biz kist ve hemanjiomları çalışmamıza dahil etmedik ${ }^{12-16}$. Biz çalışmamızda en sık görülen primer malign karaciğer tümörü olan HSK'nın tanısında ve diğer lezyonlardan ayırt edilmesinde ADC değerlerinin etkisi araştırdık.

Çalışmamızda elde ettiğimiz sonuçlara göre HSK lezyonlarının ortalama ADC değeri $836 \pm$ $182 \mathrm{x} 10-6 \mathrm{~mm} 2 / \mathrm{sn}$, kolanjiokarsinom lezyonlarının ortalama ADC değeri $801 \pm 239$ x10-6 mm2/sn, metastaz olan lezyonların ortalama ADC değeri ise $923 \pm 279 \times 10-6$ $\mathrm{mm} 2 / \mathrm{sn}$ olarak saptandı. Çalışmamızda en düşük ADC değerlerini HSK ve kolanjiokarsinomda elde ettik. İstatistiksel değerlendirmede "HSK ile kolanjiokarsinom" ve "HSK ile metastaz" arasında ADC değerleri açısından anlamlı bir fark saptamadık. Sun ve ark. $^{13}$ tarafından yapılan benzer bir çalışmada karaciğer metastazlarında ADC değerlerinin HSK'dan daha yüksek olduğu bildirilmiştir. Bu durumun metastatik lezyonlardaki nekroz varlığına bağlı olabileceğini belirtmişlerdir. Çalışmamızda $20 \mathrm{FNH}$ lezyonunda ise ortalama ADC değeri 1202,9 $\pm 139,3 \times 10-6 \mathrm{~mm} 2 / \mathrm{sn}$ olarak ölçülmüş olup, HSK ile FNH arasında istatistiksel olarak anlaml fark saptadık. Bruegel ve ark. ${ }^{4}$ yaptıkları bir çalışmada metastaz, HCC ve FNH arasinda anlaml fark olmadığını, diğer tüm fokal lezyonlar arasında ise anlamlı fark olduğunu bildirmişlerdir. Yine Ergelen ve ark. ${ }^{17}$ benzer şekilde HCC ve FNH arasında anlamlı fark olmadığını bildirmişlerdir. Farklı olarak, Gelebek Yılmaz ve ark. ${ }^{18}$ FNH ve HCC'nin ADC değerleri arasında istatistiksel olarak anlaml bir fark bildirmişlerdir. Bizim çalışmamızda da HCC ile metastaz arasında anlamlı fark bulunamazken, HCC ile FNH'ın ADC değerleri arasında anlamlı fark mevcuttu. Yapılan bu çalışmalarda tüm hastaların histopatolojik tanısı mevcut olmayıp, radyolojik tanısı olan hastalar da çalışmaya dahil edilmişti. Bizimle benzer sonucu elde eden Gelebek Yılmaz ve ark.18 'nın çalıșmasında da sadece HCC'lerin bir kısmının histopatolojik tanısı mevcut olup, diğer lezyonların yalnızca radyolojik tanısı mevcuttu. Biz ise tüm bu çalışmalardan farklı olarak, bütün lezyonları sadece histopatolojik tanısı mevcut olanlardan seçtik ve inceledik. Bu durum çalışmamızın güvenilirliğini artıran bir faktördür.

Çalışmamızda bazı kısıtlılıklar vardı. Biz benign lezyonlar olan kist ve hemanjiomları çalışmamıza dahil etmedik. Zaten bilindiği üzere kist ve hemanjiomlarda belirgin diffüzyon artışı vardır ve bu lezyonların ADC değerlerinin çok yüksek olduğu konusunda literatürde görüş birliği vardır ${ }^{12-16}$. Bunun yanı sıra adenom ve daha nadir görülen diğer fokal karaciğer lezyonlarının sayısı toplumda çok az olup, nadir görülen bu lezyonlar için bir değerlendirme yapamadık. Ayrıca sadece histopatolojik tanısı olan hastaları çalışmamıza dahil ettiğimizden, bu durum hasta sayılarımızı kısıtlamıștır. İleride bu konuda daha fazla hasta sayısı ile ve daha nadir lezyonların da dahil edildiği çalışmalar yapılabilir.

Sonuç olarak, HSK'yı FNH'dan ayırt etmede ADC değerleri tanıya ek katkı sağlarken, HSK'yı kolanjiokarsinom ve metastazdan ayırt etmede ADC değerleri tanıya ek katkı sağlamamaktadır.

Çıkar Çatışması Beyanı: Yazarlar çıkar çatışması olmadığını bildirmişlerdir.

Finansal Destek: Bu çalışma her hangi bir fon tarafından desteklenmemiştir.

Declaration of Conflicting Interests: The authors declare that they have no conflict of interest.

Financial Disclosure: No financial support was received. 


\section{KAYNAKLAR}

1. Le Bihan D, Turner R, Douek P, Patronas N. Diffusion MR imaging: clinical applications. AJR Am J Roentgenol. 1992; 159: 591-9.

2. Demir OI, Obuz F, Sağol O, Dicle O. Contribution of diffusion-weighted MRI to the differential diagnosis of hepatic masses. Diagn Interv Radiol. 2007; 13: 81-6.

3. Müller MF, Prasad P, Sievert B, et al. Abdominal diffusion mapping with use of a whole-body echoplanar system. Radiology. 1994; 190: 475-8.

4. Bruegel M, Holzapfel K, Gaa J, et al. Characterization of focal liver lesions by ADC measurements using a respiratory triggered diffusion-weighted single-shot echo-planar MR imaging technique. Eur Radiol. 2008; 18: 477-85.

5. Morin SH, Lim AK, Cobbold JF, Taylor-Robinson SD. Use of second generation contrast-enhanced ultrasound in the assessment of focal liver lesions. World J Gastroenterol. 2007; 13: 5963-70.

6. Brancatelli G, Federle MP, Grazioli L, Carr BI. Hepatocellular carcinoma in noncirrhotic liver: CT, clinical, and pathologic findings in 39 U.S. residents. Radiology. 2002; 222: 89-94.

7. Ikeda K, Saitoh S, Koida I, et all. Imaging diagnosis of small hepatocellular carcinoma. Hepatology. 1994; 20: 82-7.

8. Küçükapan A, Keskin S, Keskin Z, Poyraz N. Hepatosellüler karsinomda radyolojik algoritma ve görüntüleme yöntemleri. Genel Tıp Derg 2014; 24: 1627.

9. Itai $Y$, Ohtomo K, Furui S, et al. Noninvasive diagnosis of small cavernous hemangioma of the liver: advantage of MRI. AJR Am J Roentgenol. 1985; 145: 1195-9.
10. El-Serag HB, Marrero JA, Rudolph L, Reddy KR. Diagnosis and treatment of hepatocellular carcinoma. Gastroenterology. 2008; 134: 1752-63.

11. Phongkitkarun S, Srianujata T, Jatchavala J. Supplement value of magnetic resonance imaging in small hepatic lesion $(<$ or $=20 \mathrm{~mm}$ ) detected on routine computed tomography. J Med Assoc Thai. 2009; 92: 677-86.

12. Ichikawa T, Haradome H, Hachiya J, Nitatori T, Araki T. Diffusion-weighted MR imaging with a single-shot echoplanar sequence: detection and characterization of focal hepatic lesions. AJR Am J Roentgenol. 1998; 170: 397-402.

13. Sun XJ, Quan XY, Huang FH, Xu YK. Quantitative evaluation of diffusion-weighted magnetic resonance imaging of focal hepatic lesions. World J Gastroenterol. 2005; 11: 6535-7.

14. Yoshikawa T, Kawamitsu H, Mitchell DG, et al. ADC measurement of abdominal organs and lesions using parallel imaging technique. AJR Am J Roentgenol. 2006; 187: 1521-30.

15. Namimoto T, Yamashita Y, Sumi S, Tang Y, Takahashi M. Focal liver masses: characterization with diffusionweighted echo-planar MR imaging. Radiology. 1997; 204: 739-44.

16. Sandrasegaran K, Akisik FM, Lin C, et al. The value of diffusion-weighted imaging in characterizing focal liver masses. Acad Radiol. 2009; 16: 1208-14.

17. Ergelen R, Sahin C, Bal H, Tuney D. Diffusionweighted MRI: In differential diagnosis of liver masses. Marmara Medical Journal. 2016; 29: 145-51.

18. Gelebek Yılmaz F, Ylldırım AE. Relative Contribution of Apparent Diffusion Coefficient (ADC) Values and ADC Ratios of Focal Hepatic Lesions in the Characterization of Benign and Malignant Lesions. Eur J Ther. 2018; 24: 150-7. 